\title{
Concepções de mitos e relações com a saúde
}

\author{
Mirely Ferreira dos $\operatorname{Santos}^{1}$
}

1. Universidade Federal de Roraima, Campus Paricarana. Programa de Pós-Graduação em Ciências da Saúde (PROCISA), CEP: 693110-000, Boa Vista, Roraima, Brasil. E-mail: mirelyferreira05@gmail.com

Recebido em: 09/09/2014 Aceito em: 04/12/2014 Publicado online em PDF: 22/12/2014.

\section{RESUMO}

Concepções de mitos e relações com a saúde. Os mitos estão presentes desde a antiguidade na vida das pessoas, sendo intimamente relacionados com as crenças e a cultura de cada população. O objetivo do estudo foi analisar as concepções sobre mitos e suas relações com a saúde na perspectiva teórico-prática dos diferentes estudos presentes na literatura. O método utilizado para este estudo foi o da revisão crítica da literatura observando as publicações disponíveis nas bases Medline, Lilacs e Scielo. Foram selecionados artigos nas línguas portuguesa, inglesa e espanhola num total de 213 artigos, foram consultados também livros, teses e dissertações, do período de 1988 a 2013. Esta revisão destacou uma série de estudos de acordo com as categorias: definições sobre mitos, presença dos mitos nas religiões Candomblé e a Umbanda, concepções de mitos relacionados à saúde. Observa-se através dos séculos a existência das concepções sobre o significado da palavra mito. Muitos autores correlacionam os mitos com a evolução histórica da humanidade e associam a valores culturais, crenças e tradições. É fundamental o desenvolvimento de uma assistência da saúde voltada para as comunidades e para as pessoas que trazem consigo em particular suas crenças, origens sociais, econômicas e culturais.

PALAVRAS-CHAVE: Cultura, Tabus, Crenças, Religião.

\section{ABSTRACT}

Conceptions of myth and relationships with health. The myths are present since ancient times in people's lives, being closely related to the beliefs and culture of each population. The aim of the study was to analyze the myths and conceptions of their relations with health in theoretical and practical perspective of the different studies in the literature. The method used was the critical literature noting the publications available in Medline, Lilacs and Scielo. The articles were selected in Portuguese, English and Spanish in a total of 213 language articles were also consulted books, theses and dissertations from 1988 to 2013. This review highlighted a number of studies according to the categories: definitions of myths, presence myths in religions Candomblé and Umbanda, conceptions of myths related to health. It is observed through the centuries the existence of conceptions about the meaning of the word myth. Many authors correlate myth within the historical evolution of humanity and the associated cultural values, beliefs and traditions. It is essential to develop a health care facing communities and for people who bring in their particular beliefs, social, economic and cultural backgrounds.

KEYWORDS: Culture, Taboos, Beliefs, Religion.

\section{INTRODUÇÃO}

Os mitos estão presentes desde a antiguidade na vida das pessoas, os quais estão intimamente relacionados com as crenças e a cultura de cada população. Falar da concepção do significado da palavra mito, nos remete a ideia de ficção, fábula ou invenção, pois muitas são as histórias repassadas de geração em geração, envolvendo ritos, crenças, onde os clãs, os grupos e as comunidades usam diversas linguagens acerca dos mitos. No entanto, ao falarmos da concepção de mitos na saúde, vai além de uma fábula, pois para muitas pessoas o mito representa uma verdade sagrada para a cura, juntamente com a religião que muitos creem e tem fé.

São vários os mitos que existem no mundo.
$\mathrm{Na}$ Grécia antiga, os greco-romanos faziam uso da mitologia para desvendar as maneiras, as origens e o funcionamento do universo. Sem dúvida, a mitologia grega é uma das mais conhecidas na história da humanidade, principalmente para desvendar o sentido do homem no universo e a construção da subjetividade. Importante também são os relatos dos diversos mitos provindos das culturas americanas, ocidentais, africanas, entre outras, todos com seus significados e importância relevantes.

No âmbito da saúde muitos mitos refletem atitudes preconceituosas nas quais o ser humano está envolto por suas crenças, segredos, questões de gêneros, vínculos afetivos, agregações, entre outras. Neste aspecto, se destacam os saberes populares que muitas vezes tem o poder de curar, acalmar, melhorar e 
solucionar os problemas de saúde. Esses saberes populares são importantíssimos no contexto de cada cultura, pois é por meio deles que se evidencia a história de vida dos membros de cada comunidade; devendo estes ser respeitados principalmente pelos profissionais da saúde.

Saúde e doença são conceitos que estão presentes no dia a dia das pessoas e refletem a qualidade de vida da população, são fenômenos vivenciados culturalmente pelas sociedades, sendo que cada comunidade desenvolve maneiras diferentes de enfrentá-los. Dentre as formas de culturas tradicionais das populações surgem os tabus e mitos para lidar com questões relativas à saúde e doença. $\mathrm{O}$ conceito de saúde envolve a percepção pessoal do indivíduo sobre o seu próprio estado de saúde, aspectos físicos, psicológicos e sociais que pertencem a sua vida cotidiana e pode remeter ao completo bem estar físico, psicológico e social no ambiente em que o indivíduo encontra -se inserido, não sendo apenas a ausência de doenças.

Sabe-se que a influência cultural contribui de sobremaneira para o enfrentamento de diversas situações na vida, inclusive casos de doenças em que as populações utilizam saberes populares fortemente interligados as crenças e aos mitos para enfrentá-las. Desta forma o presente estudo teve como objetivo analisar as concepções sobre mitos e suas relações com a saúde na perspectiva teórico-prática dos diferentes estudos presentes na literatura.

\section{MATERIAL E MÉTODOS}

Foi realizada uma revisão crítica da literatura disponível nas bases Medline, Lilacs e Scielo. Para a localização dos artigos, foi utilizado "Descritores em Ciências da Saúde" (DeCS) da Biblioteca Virtual em Saúde BVS/BIREME, em português, e seus congêneres em espanhol e inglês para os temas cultura, tabus, crenças e religião. Foram selecionados artigos nos idiomas português, inglês e espanhol totalizando 213 artigos. Foram consultados também livros, teses e dissertações, do período de 1988 a 2013.

Os dados foram organizados nas seguintes categorias: definições sobre mitos, presença dos mitos nas religiões Candomblé e a Umbanda, concepções de mitos relacionados à saúde. Foi realizada uma análise crítica do conteúdo de acordo com cada categoria, tendo como base a literatura consultada.

\section{RESULTADOS E DISCUSSÃO}

\section{DEFINIÇÕES SOBRE MITOS}

De acordo com Eliade (2006), “o mito é uma realidade cultural extremamente complexa, que pode ser abordada e interpretada através de perspectivas múltiplas e complementares".

Entre todos os conjuntos mitológicos já registrados por historiadores e antropólogos pode-se perceber uma característica comum: o mito sempre conta histórias do tempo primordial, a época da criação, precedente à realidade em que vivemos, por isso distante e inacessível. Seus protagonistas são em geral deuses ou entes sobrenaturais agindo para a criação, transformação e definição do mundo, sendo ao mesmo tempo exemplos e justificativas de grande parte da moral, da tradição e dos costumes da cultura que os engendrou. No entanto, o que mais interessa para esse ensaio é o fato de que os mitos explicam o mundo a partir das concepções de realidade próprias de cada cultura, deixando entrever em suas histórias um modo particular de compreender e relacionar os elementos de seu mundo (Trujillo 2013).

Quando se trata sobre mitos é importante compreendermos o significado de cultura, pois ambos estão interligados e fazem parte do mesmo contexto. A cultura na qual a pessoa nasceu e está inserida em cada população constitui uma das influências sobre as crenças, tabus, ritos e mitos. Helman (2009) em um de seus capítulos sobre a Abrangência da Antropologia Médica, aborda o significado de cultura quando relata que:

\footnotetext{
"a origem da cultura tem influência importante em muitos aspectos da vida das pessoas, incluindo crenças, comportamento, percepções, emoções, linguagem, religião, rituais, estrutura familiar, dieta, modo de vestir, imagem corporal, conceitos de espaço e de tempo e atitudes em relação a doença, dor e outras formas de infortúnio - todos podendo ter importantes implicações para a saúde e os cuidados de saúde" (Helman, 2009).
}

A partir dessas definições, pode-se estabelecer a importância dos termos cultura e 
mitos, pois não tem como discutir o mito sem antes fazermos uma correlação com cultura. A cultura envolve as maneiras e comportamentos que os seres humanos se expressam e vivem no cotidiano, pois todo ser humano nasce, se desenvolve e cresce sob as influências diretas do contexto social em que está inserido.

Para Silva (2013), "o mito enfoca a cultura e a natureza para ser interpretado como uma atividade coletiva, via de autoconhecimento da alma humana. Mito e arte são universos que auxiliam o homem a ultrapassar os horizontes, e assim, alcançar esferas de percepções".

Segundo Eliade (2006), "compreender a estrutura e função dos mitos nas sociedades tradicionais não significa apenas elucidar uma etapa na história do pensamento humano, mas também compreender melhor uma categoria dos nossos contemporâneos".

Os saberes populares se destacam dentro do senso comum das tradições em que vivem. Com base nas tradições as pessoas mantêm as regras sociais, os comportamentos e modos de viver. $O$ significado da palavra mito compreende todas essas categorias que envolvem as culturas, assim também como as tradições dentro da realidade geral em que as populações estão inseridas; a partir de tais conceitos podemos considerar que os mitos foram a base para as formas de vida e as tradições compreenderem as realidades.

\section{PRESENÇA DOS MITOS NAS RELIGIÕES}

\section{CANDOMBLÉ E A UMBANDA}

No Brasil o Candomblé, uma religião trazida da África durante a escravidão, que utiliza de forma bastante significativa os mitos, demonstrando a realidade da religião e cultura desses povos através dos orixás mostrando as divindades protetoras através dos elementos da natureza.

Segundo Oliveira (2003), o candomblé é tradição, o culto e a cultura dos orixás. Possui um caráter extremamente humanista que visa afastar dos seres humanos pensamentos intolerantes, preconceituosos e de submissão, independentemente de sua cor, origem social, sexo ou crença religiosa. É uma religião que busca a comunhão entre os seres humanos e a natureza, levando-os a reencontrar sua força vital. O sistema ancestral africano estabelece que cada um de nós devam possuir um Orukó (nome), um Oriki (sobrenome familiar) e um Orilê (totem de origem), que visam fortalecer a identidade de cada pessoa.

Os representantes do catolicismo no Brasil, para aceitarem no país uma religião pagã que não poderia ser eliminada tão facilmente, criaram correspondências entre os santos católicos e os orixás africanos, como tentativa de cooptá-los à igreja. No entanto, estes mitos não compartilham uma visão de mundo semelhante, o que gerou inúmeras incompreensões e consequentemente recriações em relação aos mitos originais, vindos da África. A primeira grande diferença é que na igreja católica há a crença em um Deus único e todo-poderoso, enquanto o candomblé prevê um grande panteão de orixás, que são entes autônomos e dotados de uma personalidade constituída de pontos fortes e pontos fracos, como os deuses da mitologia greco-romana. A partir disto surge algo talvez ainda mais importante e revelador sobre o contato entre as duas religiões: para a religião cristã, o bem e o mal, o certo e o errado, o céu e o inferno são elementos inquestionáveis muito bem definidos. O candomblé, por sua vez, tem uma compreensão menos dualista da realidade: o bem e o mal, por exemplo, são elementos que permeiam os orixás de forma geral, ainda que cada um deles possa eventualmente ter uma predisposição maior a um ou a outro (Trujillo 2013).

Segundo Mattos (2007), “o candomblé é:uma forma de expressão religiosa, [...] bastante complexa na África ocidental, incluindo templos em homenagem as divindades, uma hierarquia entre os sacerdotes e rituais, como procissões e manifestações com toques e tambores".

No Brasil, além do Candomblé destaca-se a Umbanda que muitas pessoas utilizam como uma combinação de cultos africanos, espiritismo e catolicismo. Os rituais e uso de ervas são característicos em ambas as religiões, onde a Umbanda se destaca pelo uso do toque dos tambores, danças e ritos, sendo que muitas pessoas praticam Candomblé/Umbanda em busca de curas. Portanto, podemos considerar que as referidas religiões utilizam-se de ritos espirituais, mágicos e míticos.

A Umbanda, como todos os cultos africanos, é repleta de símbolos e mitos situação típica das culturas "primitivas", como consideram alguns estudiosos da linguagem simbólica. Os orixás, representando divindades 
protetoras relacionadas aos elementos da natureza, possuem histórias exóticas em que são narrados fatos da sua origem e da sua atuação no mundo, entre si e junto às pessoas, configurando-se, portanto, como figuras mitológicas que realizam feitos diversos, simbolizando criação, proteção, cuidado, poder, castigo e diversas atitudes, valores e sentimentos perante os homens. Trata-se realmente de uma mitologia africana, de toda a África negra, que possui, todavia, diferenças de nomes, símbolos, práticas e mitos, em razão da diversidade das nações dentro do continente africano (Silva 2012).

É importante ressaltar que as pessoas também deveriam fazer o acompanhamento com os médicos (medicina científica) diante das situações de doenças. Mesmo sabendo do poder das curas espirituais e do uso das ervas em busca da cura que as religiões Umbanda/ Candomblé apresentam é fundamental que haja a interação com os médicos no processo de busca pela melhoria do estado de saúde de qualquer indivíduo, independentemente de cor, raça, religião. Vale ressaltar que atualmente os próprios terreiros de Umbanda/Candomblé dão relevância para essa importância das pessoas não abandonarem o tratamento médico.

\section{CONCEPÇÕES DE MITOS RELACIONADOS À SAÚDE}

O corpo não é somente uma entidade biológica, mas um fenômeno cultural e histórico. A experiência do viver se torna, portanto, uma interpretação ativa do ambiente externo e ao mesmo tempo de produção e expressão deste. $\mathrm{O}$ caminho biológico não está sendo negado, porém é considerado dentro de análise mais ampla, dedicada à dimensão histórica e cultural do fenômeno. A incorporação individual é o ponto de partida para a procura do conhecimento popular da doença e a exploração do seu universo simbólico sociocultural. A força da representação biológica do corpo e da doença deve levar em consideração o universo das premissas culturais que a sabedoria popular oferece aos seus atores sociais, os recursos intelectuais dos pacientes (Magnani et al. 2007).

De acordo com Helman (2009), as doenças populares são mais do que agrupamentos específicos de sintomas e sinais físicos. Elas também têm uma variedade de significados simbólicos - morais, sociais ou psicológicos para aqueles que sofrem delas. Em alguns casos, elas ligam o sofrimento do indivíduo a alterações no ambiente natural ou a obras de forças sobrenaturais. Em outros casos, o quadro clínico das doenças é um modo de expressar, de uma forma culturalmente padronizada, que o sofredor está envolvido em conflitos sociais, como desarmonia com familiares, amigos ou vizinhos.

Os sentidos sociais produzidos em torno da doença se tornam símbolos que determinam específicas dinâmicas sociais, pois é nas relações entre os indivíduos que estes se definem, se redefinem e se confirmam constantemente. Nas relações sociais esses símbolos tornam-se legítimos, agem e se manifestam. Os mitos, as crenças populares, os medos, a experiência pessoal sobre o fenômeno da doença são fatores que acionam os mecanismos humanos (Magnani et al. 2007).

Com base nesses dados observa-se que muitas pessoas acabam confundindo ambos os conceitos de tabu e mito ou as vezes consideram ser a mesma coisa; sendo que cada termo tem sua diferenciação e seu significado, pois ao tratar sobre tabu nos remete situações proibidas. Quando se trata de mitos observa-se que estes estão muito direcionados à maneira de comportamento da sociedade, suas crenças e costumes de enfrentar uma de terminada situação.

Essa definição do conceito de tabu é bem distinguida por Buxó (1988), quando relata que o conceito de tabu, na literatura antropológica, refere-se a indivíduos, coisas ou palavras cuja qualidade são objetos de temor ou suscetíveis à proibição e, em qualquer circunstância, os tabus são mais restritivos a respeito do comportamento interativo da mulher. Luz et al. (2007) afirmam que para algumas mulheres, por exemplo, é tabu lavar a cabeça no puerpério, enquanto eliminam lóquios. A perda sanguínea é considerada perigosa, e a mulher se resguarda de lavar a cabeça para não reverter este sangramento vaginal para a cabeça. Caso isso ocorra, a mulher poderá, consequentemente, ficar louca.

De acordo com Luz et al. (2007), o período de resguardo refere-se às ações de guardar, cuidar com proteção em que a mulher permanece em repouso de três a trinta dias, aproximadamente. Esta proteção é feita por cuidados pós-parto em uma experiência que implica no envolvimento tanto de fatores 
maternos quanto dos relacionados ao recémnascido. Os tabus referentes a esse tema são apresentados nas falas das mulheres: recaída; o mal-dos-sete-dias e a proteção do quebrante. Com a prática da hospitalização para o parto, muitos dos tabus relativos ao pós-parto passaram a ser questionados ou caíram em desuso pelas mulheres.

Outra forma que se pode correlacionar ao tabu é durante o período menstrual em que muitas mulheres consideram não poder lavar a cabeça no primeiro da menstruação. Muitas também consideram que não podem ingerir determinados alimentos porque vão influenciar no aumento do fluxo sanguíneo ou provocar cólicas menstruais, como é o caso da ingestão de frutas cítricas como o limão que se atribui o aumento do fluxo menstrual e também da manga que as mulheres consideram serem precursoras de cólicas menstruais.

Helman (2009) menciona que a dieta errada também pode causar problema de saúde; por exemplo, o "sangue fino" e a pressão arterial baixa no sul dos Estados Unidos são atribuídos à ingestão excessiva de alimentos muito ácidos ou adstringentes, como limão, vinagre, picles, azeitonas ou chucrute, enquanto o "sangue grosso" resulta da ingestão excessiva de alimentos ricos, especialmente carne vermelha. Em outro estudo relatado por Nakano (2003), um quarto das mulheres entrevistada acreditava que a alimentação devia ser alterada durante a menstruação para evitar problemas de saúde. Por exemplo, elas diziam que os doces mantinham o fluxo menstrual por mais tempo, enquanto outros alimentos faziam-no cessar, resultando em cólicas menstruais, esterilidade, derrames, ou "tuberculose rápida".

Segundo Leal (1995), no relacionamento conjugal, existe situações tabus que indicam a relação direta entre fluxo menstrual e prática de saúde. A prática de resguardo menstrual difundida entre as mulheres de classes populares é a de que a menstruação é uma "forma de eliminar as impurezas, uma válvula de escape". Faz parte do equilíbrio das coisas, o sangue que está dentro tem que sair, fluir.

Em relação aos mitos, Buxó (1988) descreve que os mitos, por sua vez, fazem parte das interpretações que cada sociedade tem sobre sua realidade. A elaboração mítica tem por objetivo justificar, racionalizar e legitimar realidades socioculturais.

Dentro do contexto da saúde existe uma variedade de mitos que na maioria das vezes são passados de bisavós/mães/filhas e assim sucessivamente de geração em geração. É possível observar as fortes influências exercidas pelos mitos direcionados a saúde quando Ravelli (2004) relata que muitos são os ritos e mitos pertinentes à gestação e, consequentemente, ao cuidado prestado ao recém-nascido. Os saberes populares norteiam a história familiar, sendo que esses mitos e ritos foram utilizados pelas gerações passadas, visando a obtenção da cura de alguma patologia, mal-estar ou ferimentos, entre outras coisas.

Uma crença popular bastante difundida desde a antiguidade, quanto aos cuidados com o recém-nascido, é a utilização do pó de café no coto umbilical (Marques et al. 2011). Prática totalmente desaconselhável dentro do âmbito dos saberes científicos da saúde, porém comuns e que evidenciam a influência de um ser na vida de outro. Muitas vezes a gestante recebe a orientação que não se deve fazer uma prática deste tipo, mas por influência de uma avó ou mãe, acaba realizando. Ainda dentro do panorama sobre os cuidados com o recémnascido, podemos destacar os mitos e crenças direcionados ao aleitamento materno; onde consecutivamente ouvimos as mães falarem: que o leite é fraco; é insuficiente; o bebê não quer pegar o peito; o leite do peito não mata a sede do bebê; amamentar deixa os seios caídos e feios; dentre outros.

Com relação ao aleitamento materno Souza \& Almeida (2005), destacam que "a figura do leite fraco consolidou-se socialmente, sendo um valor cultural aceito e repassado entre várias gerações". Assim,

\footnotetext{
os mitos e as crenças relacionados à lactação fazem parte do nosso cotidiano há muitos séculos. Eles constroem o significado do ato de aleitar para a mulher por meio da herança sociocultural adquirida através da vivência dessa mulher em sociedade - transmissão de valores por pessoas próximas ou mesmo pela observação de mulheres que estão passando por essa mesma situação (Marques et al. 2011).
}

Situações nas quais mulheres consideram seu leite fraco muitas vezes se originam pelo simples fato de uma "má pega" do bebê, pois durante o período da amamentação a mãe deve ser orientada quanto aos principais cuidados com o recém-nascido, inclusive a "boa pega" do bebê para amamentar. Devendo ser de 
responsabilidade dos profissionais da saúde repassar esses cuidados para que a mãe adquira hábitos e costumes direcionados para as práticas corretas e não deixe as influências mitológicas agirem no seu cotidiano interferindo no processo da amamentação.

Segundo Nakano (2003), o mito de o leite não sustentar o bebê - por ser pouco - pode estar apoiado no choro do bebê, que geralmente é associado à fome ou ao fato de o leite não estar sendo adequado às necessidades da criança. Ravelli (2004) considera que,

a falta de informações faz com que muitos executem alguns mitos e ritos primários que acarretam influências diretamente ligadas ao cuidado de si e do outro. No entanto, outras pessoas podem conhecer esses saberes populares, porém não os praticam em seus contextos familiares, relatando, apenas, a eficácia desses mitos e ritos na história familiar (Ravelli, 2004)

É importante salientar que muitas afirmações não são consideradas mitos propriamente ditos, mas sim concepções que podem influenciar negativamente a mulher. Exemplo disto ocorre em algumas situações durante $o$ ato de amamentar quando há uma pressão psicológica exercida sobre a mesma, quanto à estética corporal, que acabam gerando responsabilidade e culpa.

Sabe-se que o ser humano reage de diferentes formas nos casos de doenças e que cada indivíduo reconhece o seu estado de doença interpretando através de respostas culturais, as quais refletem justamente seus saberes populares dentro do contexto de saúde/ doença e são esses saberes que assumem o papel principal na codificação dos agravos a saúde.

A primeira abordagem do homem à doença é, portanto, direcionada pelas medidas de avaliação própria: o medo da morte é a primeira reação. Certamente a convivência com o ambiente médico, no percurso do tratamento, interfere nas informações culturais do paciente e as influências, podendo inclusive mudar a percepção da patologia e de suas perspectivas, sem, entretanto, anular as referências primárias (Magnani et al. 2007).

Cada ser humano tem uma concepção própria sobre a doença, no entanto, observa-se que ambos trazem consigo uma particularidade em comum que é a maneira como a maioria das pessoas relaciona suas experiências pessoais, culturas, tradições e mitos diante da presença de uma determinada doença.

De acordo com Minayo (1992) saúde e doença expressam uma relação que "perpassa o corpo individual e social, confrontando-se com turbulências do ser humano enquanto ser total". São fenômenos clínicos e sociológicos vividos culturalmente, porque as formas como a sociedade os experimentam, cristalizam e simbolizam a maneira de enfrentá-los. É preciso entender que, ao ampliar as bases conceituais, as ciências sociais da saúde, não se tornam "menos científicas" mas, aproximam-se dos contornos reais dos fenômenos em estudo. Ainda dentro desse contexto, Luz et al. (2007), abordam que, se a ciência é uma forma de abordagem dominante, nem por isso é exclusiva e conclusiva, pois, para as questões humanas, além das ciências, buscam-se soluções concomitantes aos mitos, diferentes formas religiosas e sistemas filosóficos.

$\mathrm{Na}$ visão de Magnani et al. (2007), "a fé assume um papel fundamental na abordagem da doença, pois se torna instrumento justificativo da própria condição existencial e força psicológica para aceitar os próprios problemas de saúde e as dificuldades ligadas a estes".

Os pacientes lidam constantemente com os dilemas que abordam as informações repassadas pelos médicos nos sistemas de saúde e por muitas vezes expressão seus medos e angustias por não compreenderem determinada situação. Muitos são aqueles indivíduos que, por serem mal compreendidos ou interpretados, preferem optar por utilizarem sua fé religiosa e mitos populares.

Com o conhecimento adquirido no ambiente dos serviços de saúde ao longo do tempo, o indivíduo pode ter os instrumentos cognitivos adequados para entender a circunstância da doença de forma mais científica e abandonar os medos ligados aos mitos populares. Oferecer ao paciente uma perspectiva racional pode mudar a percepção que ele tem do próprio estado de saúde e do seu potencial social; o conhecimento é o único instrumento eficaz para combater os mitos culturais que são a fonte de estigma do indivíduo (Magnani et al., 2007).

O comportamento do indivíduo dependerá da maneira como ele lida com as informações, agindo de acordo com seus valores, crenças, costumes, fé e mitos. É nessa perspectiva que vemos o destaque da influência dos saberes populares, sendo fundamental o papel das 
crenças religiosas principalmente diante do enfrentamento das doenças. A religião é utilizada pelo paciente como instrumento de identificação da realidade, servindo de suporte para o enfrentamento dos sofrimentos advindos das doenças.

No mundo científico, a ciência é o valor fundamental e a prática popular uma experiência "primitiva", sem embasamento, ancorada na magia e em crenças supersticiosas. A política de saúde reforça a cientificidade do conhecimento. Mas toda vez que se pergunta a razão da permanência dos saberes populares, a resposta os relega ao folclore, qualifica-os de resíduo, fragmento pouco relevante, próprio das pessoas simples. No entanto, acredita-se que olhar o fenômeno só na perspectiva do universo vivido anula sua riqueza e escamoteia suas múltiplas vertentes. Além disso, o problema não é opor-se à ciência, mas entender que, na pluralidade da sociedade, há distintas maneiras de respeitar o outro, diferentes modos de organizar o sensível. Não se trata de conceder superioridade ou inferioridade a uma ou outra forma de conhecimento, porque são apenas modos diferentes de encarar e enfrentar a realidade (Luz et al. 2007).

É importante ressaltarmos que os vários significados culturais sobre as doenças estão profundamente incorporados na sociedade brasileira. O sentido popular difundido identifica o fenômeno biológico das doenças diante da realidade sociocultural de cada ser, baseando-se em referências não médicas. As interpretações populares são avaliações sociais eficazes pelo fato de serem reconhecidas e compartilhadas no sentido popular (Luz et al. 2007).

Segundo Gazzenelli (2005) acredita-se que o conceito de saúde/doença para os profissionais que atuam no campo da saúde coletiva precisa ser revisto tanto na literatura que aborda os saberes populares quanto nas comunidades. Diferentes axiomas têm norteado as práticas de educação em saúde. Já Luz et al. (2007) em um estudo realizado com mulheres sobre mitos e tabus da maternidade, mostra a fala das mesmas quando ambas afirmam que, fica-se doente por dois motivos: o primeiro é por causa natural. $\mathrm{O}$ indivíduo adoece por razões relativas ao ambiente externo que atinge o interior do seu corpo - "pegou no vento; ficou no sereno; ficou no sol; comeu alguma coisa estragada; foi picada; pegou coisa do chão sujo"; o segundo, por fator sobrenatural, provocado por espíritos que atuam sobre o corpo - "está tomado; botaram quebrante; foi mau olhado".

O profissional da saúde deve considerar cuidadosamente a força das referências culturais incorporadas por cada indivíduo. Devendo-se levar sempre em consideração os pensamentos e opiniões da sabedoria popular; os quais influenciam a abordagem da doença para a partir dessa premissa poder integrar às informações médicas.

Cabe aos profissionais da saúde respeitar as crenças e mitos que os pacientes venham demonstrar, pois muitos acabam criando uma barreira diante de uma determinada doença e muitas vezes não são compreendidos de maneira equivalente aos seus costumes. Nestes casos, oferecer ao paciente uma perspectiva racional pode mudar a sua percepção que tem a respeito de determinado mito que venha a se tornar um obstáculo para seu tratamento.

\section{CONSIDERAÇÕES FINAIS}

Os mitos e tabus permeiam o cotidiano de muitas pessoas, sejam por terem adquirido de seus ancestrais ou criado no meio social ao qual o indivíduo está inserido. Muitos são repassados de geração em geração como os mitos relacionados a amamentação que estão envoltos por uma construção social e cultural da forma como as mães devem criar os filhos, sendo repassados e sustentados para seus descendentes.

Muitas populações utilizam de seus saberes populares associados aos mitos para combater as doenças, como as religiões do Candomblé e Umbanda que focalizam o uso de plantas e práticas de rituais para o enfretamento dos problemas, sendo ambas dotadas de costumes que devem ser respeitados de acordo com suas crenças. Os mitos compreendem um embasamento de conhecimentos desenvolvido por estas culturas, sendo que são interpretados por muitos de maneira errônea, pois esses conhecimentos míticos não se baseiam diretamente em conhecimentos científicos, o que gera muitas vezes falta de compreensão, principalmente por parte dos profissionais da saúde.

Pode-se concluir através da revisão de literatura realizada no presente estudo que é fundamental o desenvolvimento de uma assistência da saúde voltada para as comunidades e para as pessoas que trazem consigo em particular suas crenças, origens 
sociais, econômicas e culturais. Sendo que muitas vezes passam despercebidas nos ambientes hospitalares em que a maioria dos profissionais visam o caráter prático do atendimento, faltando a interação com o paciente e dando pouca atenção as suas crenças, costumes, medos e mitos. Dessa forma, é importante que haja o estabelecimento do respeito diante das opções de tratamento que os pacientes podem demonstrar, seja no âmbito da saúde física, psicológica ou espiritual.

\section{AGRADECIMENTOS}

A minha família, por todo incentivo e esforço desprendido, em especial a minha irmã Jacinta Ferreira pelo apoio e colaboração. A Janimere Soares pelas orientações.

\section{REFERENCIAS BIBLIOGRÁFICAS}

Buxó, M. J. R. 1988. Antropologia de la mujer: cognição, lengua e ideologia cultural. Barcelona: Anthropos, $218 \mathrm{p}$.

Eliade, M. 2006. Mito e realidade. São Paulo: Editora Perspectiva. $6^{\text {a }}$ ed. $184 \mathrm{p}$.

Gazzenelli, M. F. 2005. Educação em saúde: conhecimentos, representações sociais e experiências da doença. Cadernos de Saúde Pública 21 (1): 200206.

Helman, C. G. 2009. Cultura, saúde e doença. 5.ed. Porto Alegre: Artmed, 432 p.

Leal, O. F. 1995. Sangue, fertilidade e práticas contraceptivas. Porto Alegre: UFRGS, 174 p.

Luz, A. M. H.; Berni; N. I. O. \& Selli, L. 2007. Mitos e tabus da maternidade: um enfoque sobre o processo saúde-doença. Revista Brasileira de Enfermagem 60 (16): 42-48.

Magnani, C.; Oliveira, B. G. \& Gontijo, E. D. 2007. Representações, mitos e comportamentos do paciente submetido ao implante de marcapasso na doença de Chagas. Cadernos de Saúde Pública 23 (7): 16241632.

Marques, E. A.; Cotta, R. M. M. \& Priore, S. E. 2011. Mitos e crenças sobre o aleitamento materno. Revista de Ciências \& Saúde Coletiva 16 (5): 2461 - 2468.

Mattos, R. A. 2007. História e cultura afro-brasileira. São Paulo: Contexto, $161 \mathrm{p}$.

Minayo, M. C. S. 1992. O desafio do conhecimento: pesquisa qualitativa em saúde. São Paulo: Hucitec/ Rio de Janeiro: Abrasco, 269 p.

Nakano, M. A. S. 2003. As vivências da amamentação para um grupo de mulheres: nos limites de ser "o corpo para o filho" e de ser "o corpo para si" Cadernos de Saúde Pública 19 (2): 355-363.

Oliveira, F. 2003. Uma reflexão Sobre a Saúde da População Negra no Brasil. In: Religiões afrobrasileiras e saúde, São Luís, Projeto Ató-Irê: Centro de Cultura Negra do Maranhão, $151 \mathrm{p}$.

Ravelli, A. P. X. 2004. Percepções de gestantes sobre a contribuição da música no processo de compreensão da vivencia gestacional. Dissertação de Mestrado, Universidade Federal do Rio Grande do Sul, Porto Alegre. $83 \mathrm{p}$.

Silva, C. L. F. 2012. As ervas nos rituais de Umbanda: magia e poder da natureza. Dissertação de Mestrado, Pontifícia Universidade Católica de Goiás, Goiânia. $215 \mathrm{p}$.

Silva, D. M. M. A. 2013. A escrita negra de Solano Trindade: movimentos de resistência e modos de identidade da consciência poética. Dissertação de Mestrado, Pontifícia Universidade Católica de São Paulo. 135 p.

Souza, L. M. B. M. \& Almeida, J. A. G. 2005. História da alimentação do lactente no Brasil: do leite fraco à biologia da excepcionalidade. Rio de Janeiro: Revinter. 117 p.

Trujillo, R. 2013. Esquinas. Dissertação de Mestrado, Faculdade de Letras, PUCRS, Porto Alegre. 135 p. 